\title{
Estudo da cooperação na equipe multidisciplinar da modalidade de equoterapia, na Associação de Pais e Amigos dos Excepcionais, no município de Pelotas/RS Study of cooperation in the multidisciplinary team of the modality of equotherapy, in the Association of Parents and Friends of the Exceptionals, in the municipality of Pelotas/RS
}

\section{Resumo}

O presente artigo apresenta um estudo sobre cooperação na equipe multidisciplinar, que participa da modalidade de equoterapia, na Associação de Pais e Amigos dos Excepcionais (APAE), no município de Pelotas, Rio Grande do Sul. O objetivo consiste em verificar a importância do estudo da cooperação entre esses profissionais e também analisar a importância do fomento de organizações, tais quais cooperativas e associações no ramo da saúde. O estudo consiste em um levantamento de dados, com aplicação de questionários com perguntas abertas e fechadas feitas aos profissionais envolvidos com a modalidade e para o embasamento do mesmo, foi realizada revisão bibliográfica. Perante o estudo, constatou-se que apesar dos profissionais do ramo da saúde não obterem, em sua formação acadêmica, estudos formais direcionados ao associativismo, cooperativismo e economia solidária, estes possuem entendimento subjetivo acerca do assunto, quanto praticam tal cooperação e ajuda mútua, compreendendo como todos esses tipos de ações são importantes. Palavras-chave: Cooperação; Princípios do associativismo; Profissionais da saúde

\begin{abstract}
This article presents a study on cooperation in the multidisciplinary team, which participates in the hippotherapy mode, the Association of Parents and Friends of Exceptional Children (APAE), in the municipality of Pelotas, Rio Grande do Sul. The aim is to verify the importance of the study cooperation between these professionals and also analyze the importance of funding organizations such which cooperatives and associations in the health sector. The study consists of a survey of data, questionnaires with open and closed questions to professionals involved with the modality and the basis of it, literature review was performed. Before the study, it was found that despite the health industry professionals do not get in their education, formal studies directed to associations, cooperatives and solidarity economy, these have subjective understanding of the subject, the practice such cooperation and mutual assistance, understanding how all these types of actions are important.
\end{abstract}

Keyword: Cooperation; Principles associations; Health professionals

Recebido: 28/10/2017 Aceito: 06/11/2017

Maria Bethânia Tomaschewski Bueno ${ }^{1}$, Maria Isabel Giusti Moreira ${ }^{2}$

${ }^{1}$ Tecnóloga em Gestão de Cooperativas pelo Instituto Federal de Educação, Ciência e Tecnologia Sul-Rio-Grandense campus Pelotas Visconde da Graça - bethaniatomaschewsky@gmail.com

${ }^{2}$ Doutorado em Ciência da Computação pela Universidade do Rio Grande do Sul - isabelmoreira@gmail.com 


\section{Introdução}

$\mathrm{O}$ presente artigo apresenta um estudo sobre a cooperação na equipe multidisciplinar, que participa da modalidade de equoterapia, na Associação de Pais e Amigos dos Excepcionais $\left(\mathrm{APAE}^{1}\right)$, no município de Pelotas, Rio Grande do Sul. Tem por objetivo verificar a importância do estudo da cooperação entre profissionais singulares, em uma associação e o quanto essa cooperação e os princípios do associativismo estão imersos nesse ambiente.

Como nesse artigo um dos profissionais analisados da equipe multidisciplinar é um fisioterapeuta e pelo fato de um dos autores ser acadêmico do curso de Tecnologia em Gestão de Cooperativas e também do curso de Bacharelado em Fisioterapia, sentiu-se a necessidade de contribuir para o estudo da cooperação no ramo da saúde, focando o estudo na modalidade de equoterapia, realizada na Associação de Pais e Amigos dos Excepcionais (APAE) do município de Pelotas, Rio Grande do Sul.

Com isso, interligam-se dois âmbitos - o da gestão e o da saúde. O estudo é um levantamento de dados, com base em Gil (2010), com aplicação de questionários com perguntas abertas e fechadas aos profissionais envolvidos com a modalidade e para o embasamento do mesmo, foi realizada uma revisão bibliográfica.

Os objetivos específicos dessa pesquisa se definem da seguinte maneira: analisar a importância do estudo de outras organizações, como cooperativas e associações e analisar como é vista a Associação, pelos profissionais da modalidade. Tais objetivos visam promover estudos futuros, os quais possam desenvolver produções científicas em que outras associações, como as APAE, possam ser beneficiadas ou contempladas.

Estudar-se a importância da cooperação entre os profissionais do ramo da saúde é bastante complexo, primeiramente porque a figura do médico, ainda nos dias atuais, é extremamente exaltada como superior aos demais profissionais do ramo da saúde. Culturalmente, existe uma distância entre os profissionais da área, isto se dá com base histórica, visto que a profissão do médico é mais antiga do que outras. A medicina tem seu registro desde $\mathrm{o}$ Paleolítico $^{2}$ (GUSMÃO, 2004, p. 2) $)^{3}$, portanto tal fato pressupõe que o médico está, dentro das relações multidisciplinares, em um nível hierárquico, muitas vezes, superior.

$\mathrm{O}$ artigo não questiona a importância de nenhum profissional nem sua atividade, mas sim faz uma observação de como é trabalhada pela associação, a cooperação entre esses profissionais. Com base nessas observações, é possível verificar como é articulada essa cooperação entre os profissionais envolvidos, na modalidade de equoterapia, na Associação de Pais e Amigos dos Excepcionais.

\section{Referencial teórico}

\subsection{Cooperação e colaboração}

Quando se abordam os temas sobre cooperação, cooperativismo ou associativismo, algumas pessoas veem neles questões inatingíveis ou até mesmo fantasiosas, ou seja, algo que não dá certo na realidade. Isso ocorre, talvez, pelo sistema econômico em que se vive, desenvolve-se psicologicamente e profissionalmente na atualidade, no qual o mundo é extremamente competitivo, exigente e as relações de poder e sucesso interferem no indivíduo e em suas relações sociais.

Com base no acima exposto depreende-se que não há quase espaço para pensamentos ou reflexões para outro modelo de vida e de mercado. A cooperação torna-se imaginária se não estudada e entendida como algo, de fato, alternativo para uma melhoria de uma comunidade e seus indivíduos.

A cooperação deve ser estudada desde os primeiros anos de vida, para que o indivíduo consiga questionar e refletir em todas as suas ações, como na comunidade que vive, tal conceito. É a maneira de desenvolver cidadãos melhores, mais conscientes econômica, social e ambientalmente. Em Lima (2006), há duas passagens transcritas abaixo que darão embasamento ao conteúdo desse artigo:

Assim, embora se admita que o conflito e a competição sejam processos intrínsecos aos sistemas sociais, considera-se a cooperação uma relação primordial, visto que, sem ela, não pode existir sociedade. No verbete do Dicionário de Ciências Sociais, o termo cooperação se define como qualquer forma de trabalho em conjunto, em contraste com concorrência ou oposição. Em economia e história social o termo é empregado (como o adjetivo cooperativo) para descrever qualquer forma de organização social ou econômica que tem por base o trabalho 
harmônico em conjunto, em oposição a concorrência (p. 04).

[...] Escreveu Smith: O homem tem oportunidades quase constantes de receber ajuda de seus irmãos e é inútil esperar essa ajuda como benevolência... não é a benevolência do açougueiro, do cervejeiro ou do padeiro que nos proporciona nosso jantar, e sim a preocupação de cada um deles com seus próprios interesses. Esboça-se aqui e na definição de Summer a sinalização de que os processos e relações cooperativas, por primordiais que sejam, admitem o conflito de interesses (p. 04).

Wincker e Molinari (2011) demonstram em seu estudo a diferenciação entre os termos de cooperação e colaboração e o quanto são equivocadamente usadas. Na Tabela 1, elaborada por Wincker e Molinari (2011), pode-se ver, de forma clara, esta diferenciação:

\section{Tabela 1-Diferenciando os conceitos}

\begin{tabular}{c|c|c|c}
\hline Estratégia & Comportamento dos autores & Sentido & Objetivos \\
\hline Competição & Concorrência/Rivalidade & Horizontal & Ganhos individuais \\
\hline Cooperação & Reciprocidade & Horizontal & Ganhos comuns \\
\hline Colaboração & Apoio & Horizontal ou Vertical & Ganhos individuais \\
\hline Coopetição & Competição+Cooperação & Horizontal & Ganhos comuns
\end{tabular}

Fonte: WINCKER e MOLINARI, 2011.

Analisando a Tabela 1, apenas detendo-se em cooperação e colaboração, verifica-se que as autoras exaltaram a diferenciação de objetivos e comportamentos dos indivíduos, nos quais a cooperação é demonstrada com o objetivo de ganhos em comum e o comportamento dos indivíduos é a reciprocidade.

Já a colaboração é demonstrada pelos ganhos individuais e o comportamento desses indivíduos, somente pelo apoio. Pode-se analisar que a cooperação engloba a colaboração, mas ela é uma estratégia com um universo maior, seus resultados atingem e beneficiam mais indivíduos, do que a colaboração.

\subsection{Cooperação na saúde}

Durante a busca de referências para esse artigo, encontrou-se dificuldade no estudo da cooperação sobre a modalidade de equoterapia, principalmente por se tratar de um ambiente próprio da área da saúde, multidisciplinar. Essa dificuldade de referências na literatura, que não permite diretrizes, no entanto, permite um olhar progressista e possibilidade de estudos evolutivos futuros.

Relacionando cooperação, saúde e o trabalho multidisciplinar na área da saúde Scherer, Pires e Schwartz (2009) realizam uma reflexão sobre o trabalho coletivo na dimensão da saúde, o comportamento dos indivíduos e o quanto essa área é complexa em gerir, padronizar processos e citam, também, a maneira como ainda persiste a questão de empoderamento de profissões. 179):

Empoderamento, segundo Baquero (2012, p.

O duplo significado que o empowerment pode assumir, segundo Gohn (2004), remete à diferenciação da utilização do termo como verbo transitivo ou intransitivo, conforme assinalado por Labonte (1994). Como verbo transitivo, empoderar envolve um sujeito que age sobre um objeto. Como verbo intransitivo, por sua vez, envolve a ação do próprio sujeito. Usado transitivamente, empoderar significa dar poder a outro, compartilhando alguns poderes que determinados profissionais devem ter sobre outros. Desta forma, o profissional é visto como agente de empoderamento, e permanece como sendo o ator controlador, definindo os termos da interação. Os indivíduos ou grupos relativamente desempoderados permanecem como objetos da relação, como os receptores da ação externa, numa atitude passiva. A afirmação "precisamos empoderar este ou aquele grupo" reforça a ação de um indivíduo/grupo sobre outro indivíduo/grupo, considerados incapazes de sua própria ação de poder. 
Outra questão que contribui para o assunto discutido nesse artigo é como as autoras, Scherer, Pires e Schwartz (2009), expõem a necessidade da cooperação nessa área, o trabalho da equipe no processo de alcance dos objetivos, mas com o empenho de cada profissional com sua singularidade se faz importante.

Gomes e Deslandes (1994) agregam para o pensamento mais didático no ramo da saúde. Tal embasamento é fundamental para que se possa ter o entendimento crítico de cada detalhe do processo proposto, destacando pontos de acordo com o objetivo, como também, aspectos que entram em conflito, isso é necessário para a reflexão de um conteúdo complexo.

Partindo-se para uma visão mais política, destaca-se Santana (2010), que trata de forma esclarecedora a importância da cooperação no ramo da saúde, mas da visão de medidas políticas entre países, a luta e obtenção de debates, ações em prol dos países mais necessitados de atenções na saúde.

Demonstra e reforça os benefícios do modelo de cooperação, intensificando a ideia de que esse é de fato, uma alternativa não somente em momentos de crise ou um plano secundário, economicamente e ou socialmente, mas sim que deve ser estudado, ofertado e compreendido pela população como modelo de vida. A sociedade deve ter acesso a esse modelo e compreender que não se trata de um modelo imaginário e sim, como um modelo real e benéfico a todos.

Na visão política tem-se também, Matuda, Aguiare e Frazão (2012), onde estes autores apresentam a reformulação dos processos entre os profissionais da saúde no Brasil, descrita na forma histórica e reflexiva em relação ao comportamento e a pontuação da cooperação entre esses profissionais.

Não há um julgamento ao artigo de Matuda, Aguiare e Frazão (2012), porém ao desenvolver conhecimentos sobre cooperação, não se deve equivocar com o termo de colaboração, de modo que, pode-se ser colaborativo sem ser cooperativo, mas ao ser cooperativo, em seu núcleo há a colaboração.

O estudo sobre cooperação deve ser cuidadoso, pois ainda há muita utilização equivocada dos termos em questão e isso gera nos receptores uma dificuldade de compreensão. Devem-se tratar suas conceituações de forma clara e objetiva, para que os destinatários e demais interessados, saibam distinguir e ter a sensibilidade de compreender tanto na literatura, quanto nas ações cotidianas tais conceitos e diferenças.

\subsection{Multidisciplinar e interdisciplinar}

Do mesmo modo que se identifica a complexidade de compreensão do cooperar e colaborar, não há distinção de forma clara da multidisciplinaridade e da interdisciplinaridade. $\mathrm{O}$ trecho abaixo, retirado de Lima (2005), possibilita a análise conjunta da cooperação, estabelecida por esse artigo, em uma equipe de profissionais singulares e o quanto cada fragmento é importante para a análise global desse ambiente.

O que se pretende com a prática interdisciplinar, não é anular a contribuição de cada área em particular, mas, apenas, uma atitude que venha a impedir que se estabeleça a supremacia de determinada área, trazendo prejuízo de outras áreas igualmente importante (LIMA, 2005, p. 27).

Com isso, respalda-se na escrita, que nenhum indivíduo no ambiente de uma cooperativa ou associação é superior aos demais. No artigo de Tavares et al. (2012), as autoras afirmam que:

O trabalho da equipe multidisciplinar visa avaliar o paciente de maneira independente e executando seus planos de tratamento como uma "camada adicional" de serviços (p. 02).

[...] o principal aspecto positivo da atuação em equipe interdisciplinar é a possibilidade de colaboração de várias especialidades que denotam conhecimentos e qualificações distintas. Assim, a integração da equipe de saúde é imprescindível para que o atendimento e o cuidado alcance a amplitude do ser humano, transcendendo a noção de conceito de saúde (p. 02).

Outra passagem de Lima (2005) foi a citação de um dos autores de grande referência na equoterapia no Brasil:

Cirillo é enfático ao dizer que a prática de equoterapia é realizada por uma equipe multidisciplinar, que trabalha de forma interdisciplinar. Está equipe deve ser mais ampla possível, composta por profissionais das áreas de: saúde, educação e equitação. A composição mínima para trabalhar com equoterapia deve ser de três profissionais, um de cada área, atuando de maneira interdisciplinar (LIMA, 2005, p. 46 apud CIRILLO, 2002). 
O trecho citado acima demonstra uma abordagem superficial sobre cooperação no ambiente de equoterapia. Ambiente este, estudado nesse artigo, o qual verifica e estimula-se a importância do estudo da cooperação em um determinado ramo. Ramo este aonde estão inseridos profissionais que, muitas vezes pelo próprio trabalho, são colocados em situações aonde a melhor opção é cooperar.

\subsection{Cooperativismo e associativismo}

O cooperativismo e o associativismo existem desde os primórdios da civilização, não na mesma forma organizacional da atualidade, mas a cooperação e a ajuda mútua entre os indivíduos, na sua forma mais crua e primitiva.

A cooperação é uma característica relevante ao analisar o instinto do próprio ser humano. Podese citar a organização dos índios, por exemplo, no Brasil antes da colonização, na sua forma de organização em tribos com ajuda mútua entre todos os membros da comunidade.

No Brasil, as primeiras experiências de cooperativismo vieram por meio de ações de padres jesuítas no sul do país no início do século XVII. Esses religiosos, utilizando-se da persuasão e movidos pelo princípio do auxílio mútuo - mutirão - que os índios brasileiros já praticavam, fundaram as reduções jesuítas: comunidades solidárias fundamentadas no trabalho coletivo com objetivo de promover o bem-estar dos membros da comunidade (OCERGS 4 , 2012).

Para Abrantes (2004) em 1659, a literatura demonstra ensaios de organizações em associações, como de Peter Cornelius Plockboy. Na Inglaterra, agora documentado, o autor cita a mais antiga cooperativa:

A mais antiga cooperativa documentada data de 1760, sendo composta por trabalhadores dos estaleiros de Woolwich e Chatam, na Inglaterra. Criada com o objetivo de moer os cereais dos associados, reduzindo os custos cobrados pelos moleiros estabelecidos (ABRANTES, 2004, p. 37).

Devido à insatisfação com a situação da economia, exploração de classes, o que gerou a Revolução Industrial, grupos de indivíduos começaram a se organizar e cooperar para uma melhoria de vida, isso ocorreu claramente nos países da França, Alemanha e Inglaterra, palco da própria revolução.

Segundo Abrantes (2004), o inglês Robert Owen tornou-se referência no cooperativismo e foi considerado o pai do cooperativismo inglês, não somente por trabalhar teoricamente, mas também por suas ações em uma época marcada pela expansão clara do capitalismo e da luta das classes dominadas contra a classe dominante.

Owen foi o primeiro a organizar cientificamente o cooperativismo, articulando-o com a sociedade. Mesmo após sucessivos fracassos, ele continuou apregoando a filosofia cooperativista como forma de reduzir a pobreza. Foi líder e teve muita influência também na formação do sindicalismo inglês. A ele atribuiu-se ainda o pioneirismo do uso do termo cooperação em oposição à competição (ABRANTES, 2004, p. 41).

Mas foi em 1844, que um grupo de indivíduos ao formar uma cooperativa marcou a literatura, no segmento, os tecelões da cidade de Rochdale (Inglaterra). Quem lê e estuda mais profundamente sobre o cooperativismo sabe que esse episódio é colocado com referencial e ponto de partida para diversos estudos. Foi um fragmento na história que impulsionou o cooperativismo.

Em 21 de dezembro de 1844, em Toad-Lane (Beco do Sapo) um grupo de 28 tecelões da cidade de Rochdale, na região de Manchester, na Inglaterra, lançou no mundo a semente do sistema econômico do Cooperativismo. Um século e meio de experiência consagrou este sistema como o maior movimento de ideias já realizado na história da humanidade (OCERGS, 2012).

Tanto as cooperativas como as associações seguem sete princípios, eles são as bases que fundamentam e direcionam essas organizações. A partir de 1995, houve uma reformulação na redação desses, segundo Branco e Morais (2014, p. 43), mas os princípios seguem os mesmos: Adesão voluntária e livre; Gestão democrática pelos membros; Participação econômica dos membros; Autonomia e independência; Educação, formação e informação; Intercooperação e Interesse pela comunidade.

$\mathrm{Na}$ associação, o princípio da adesão voluntária e livre é descrito como qualquer indivíduo que tenha interesse em participar da associação e esteja ciente das responsabilidades que essa acarretar, está apto para o ingresso. 
A gestão democrática pelos sócios traz a tomada de decisões e o controle da associação, como ponto chave para os associados. Eles controlam e participam de todos os detalhes referentes à associação. Outro ponto a ser ressaltado é de que todos os sócios são iguais, todos tem o mesmo peso de decisão.

No princípio da participação econômica, sabe-se que a associação não tem o caráter de gerar lucros, como uma empresa capitalista e também capital social como a cooperativa, tudo que for arrecadado ou doado à associação é para ser empregado em melhorias, na mesma. Caso seja dissolvida, deve ser repassado a uma outra associação, com a mesma finalidade.

A autonomia e independência, demonstra que os sócios têm a liberdade de decidirem o que for melhor para a associação, a gestão da associação pelos seus membros é de total controle dos mesmos. Obviamente, essa autonomia e independência deve estar com base na Constituição Federal.

A educação, a formação e a informação são princípios que envolvem todo o conhecimento dessa organização e fazem com que isso se propague. Os líderes devem fomentar esse conhecimento, a informação deve ser repassada aos sócios de quaisquer particularidades da associação, como também a formação deve ser estimulada para o crescimento dos próprios indivíduos e tecnicamente da associação.

A intercooperação ou o princípio da interação, compreende a ajuda entre, por exemplo, duas associações. É o fortalecimento dos laços como doutrina, cultura e organizações, unindo-se com objetivos em comum.

O interesse pela comunidade é o princípio núcleo, porque os indivíduos se agrupam com objetivos comuns, trabalham para crescimento e fortalecimento do grupo e isso tudo atribui em benefícios para a sociedade.

Com o desenvolvimento e se acentuando o entendimento pelas propostas defendidas pela cultura associativista e cooperativista, acaba-se desenvolvendo não somente a parte social, como econômica e sustentável da comunidade.

As cooperativas e associações são embasadas por sete princípios, no entanto há algumas características que as diferenciam. Para Abrantes (2004), as diferenças entre associação e cooperativa são demonstradas na Tabela 2 .

\section{Tabela 2 - Diferenças entre associação e cooperativa}

\begin{tabular}{c|c|c}
\hline \multirow{2}{*}{ Objetivos } & Associação & Cooperativa \\
\hline Patrimônio & $\begin{array}{c}\text { Sociais. Amplos e menos } \\
\text { definidos. Promove a melhoria } \\
\text { técnica, profissional e cultural dos } \\
\text { associados. }\end{array}$ & $\begin{array}{c}\text { Sociais e econômicos. Desenvolve atividades } \\
\text { produtivas, integrando pessoas na busca de } \\
\text { uma vida melhor. }\end{array}$ \\
\hline Remuneração Dos Diretores & $\begin{array}{c}\text { Não possui capital social. O } \\
\text { Patrimônio é integralmente da } \\
\text { associação. Quando um associado } \\
\text { se afasta, não recebe a sua parte. } \\
\text { Em caso de dissolução, todo o } \\
\text { patrimônio deve ser destinado à } \\
\text { outra associação semelhante. }\end{array}$ & $\begin{array}{c}\text { Possui capital social. Cada associação é dono } \\
\text { de parte do patrimônio. Quando ele se afasta } \\
\text { da cooperativa, recebe as suas quotas-partes } \\
\text { corrigidas. Em caso de dissolução da } \\
\text { cooperativa, parte do capital pode ser } \\
\text { retornado para cada associado. }\end{array}$ \\
\hline $\begin{array}{c}\text { Os diretores não podem ser } \\
\text { remunerados. Na prática, os } \\
\text { diretores têm suas despesas, } \\
\text { decorrentes do cargo, pagas pela } \\
\text { associação, como despesas gerais } \\
\text { desta. }\end{array}$ & $\begin{array}{c}\text { Os diretores podem ser remunerados, com } \\
\text { retirada pró-labore, desde que conste no } \\
\text { estatuto aprovado em assembleia geral. As } \\
\text { retiradas são controladas pelo conselho fiscal } \\
\text { da cooperativa. }\end{array}$ \\
\hline Destinos Das Sobras & $\begin{array}{c}\text { Não podem ser distribuídas aos } \\
\text { associados. Caso ocorram, têm que } \\
\text { ser inteiramente aplicadas nos } \\
\text { objetivos da associação. Em geral, } \\
\text { são usadas para festas ou compra } \\
\text { de algum bem para a associação. }\end{array}$ & $\begin{array}{c}\text { Podem ser distribuídas aos associados, na } \\
\text { proporção das quotas-partes. Isto após o } \\
\text { desconto de todos os fundos e destinações } \\
\text { obrigatórias, conforme o estatuto. Em geral, } \\
\text { as sobras são incorporadas ao capital da } \\
\text { cooperativa. }\end{array}$ \\
\hline
\end{tabular}

Fonte: Adaptado de Abrantes (2004, p. 86). 
Na associação o foco é no capital humano e pode-se salientar uma parte da Tabela 2, aonde informa que mesmo se a associação decide dissolverse, seu patrimônio irá ser destinado a outra associação de mesma finalidade. O contrário de uma cooperativa, que queira dissolver-se irá dividir todo seu capital entre seus sócios, devidamente na proporção de cada um.

\section{A Associação de Pais e Amigos dos Excepcionais de Pelotas/RS e a modalidade de equoterapia}

A Associação de Pais e Amigos dos Excepcionais (APAE) é uma associação como o próprio nome informa, de pais e amigos, de indivíduos que necessitam de um atendimento especial, de um atendimento mais específico para o seu desenvolvimento.

A APAE iniciou suas atividades no ano de 1962 ainda na sede da Escola Alfredo Dub, no próprio município de Pelotas/RS. Com um terreno doado pela Prefeitura de Pelotas, em 1984, foi concluída a nova sede no município. É uma sociedade civil, sem fins lucrativos que tem como objetivo prestar atendimento educacional, cultural e de saúde a indivíduos com deficiência física, mental e portadores de algumas síndromes.

A Associação mantém-se, principalmente, com o trabalho de telemarketing, para arrecadação de benefícios, bem como do serviço de lavandeira ofertado à sociedade, o qual era anteriormente trabalhado como oficina aos alunos, mas a partir do ano de 1996, devido a demanda e otimização de captação de recursos, foram contratados serviços especializados e, assim, tornando-se uma fonte de geração de renda e valor. Outros benefícios são adquiridos em realizações de eventos na comunidade e verbas provenientes do Governo municipal, estadual e federal.

A modalidade de equoterapia, foco desse artigo, é trabalhada desde o ano de 1996 em parceria com a Associação Rural de Pelotas, por questões de estrutura física. A equipe da equoterapia da APAE, no município de Pelotas/RS, é composta por: Assistente Social, Auxiliar Guia, Estagiário, Equitador, Fisioterapeuta, Fonoaudiólogo, Médico Neurologista, Pedagogo, Psicólogo e Psicopedagogo. E é composta, também, por dez cavalos, sendo desses $90 \%$ ou 9 da raça Crioula ${ }^{5}$. Todos os cavalos foram doados para a Associação ${ }^{6}$.
Não se pode deter-se somente em ações do próprio homem, por isso demonstrar-se, também, o quanto o cavalo é cooperativo na equoterapia, excluindo a visão errônea que se têm de que esse animal é somente um instrumento de trabalho, pois coopera efetivamente na equipe, nos movimentos do seu andar. $\mathrm{Na}$ literatura, observa-se a prática de equoterapia descrita por Hipócrates já nos anos de 458-377 Ac ${ }^{7}$. Em 1747, foi descrito por Samuel T. Quelmaz, pela primeira vez os benefícios da prática da andadura no cavalo (SEVERO, 1997, p. 03).

Entretanto, no Brasil a Associação Nacional de Equoterapia (ANDE - BRASIL, 2015) ${ }^{8}$ foi fundada somente no ano de 1989 e o reconhecimento da equoterapia, no país, aconteceu pelos órgãos: Conselho Federal de Medicina, em 6 de Abril de 1997, e pelo Conselho Federal de Fisioterapia e Terapia Ocupacional, em 27 de Março de 2008 (ANDE - BRASIL, 2015).

Segundo a Associação Nacional de Equoterapia (ANDE - BRASIL, 2015), Equoterapia:

É um método terapêutico que utiliza o cavalo dentro de uma abordagem interdisciplinar nas áreas de saúde, educação e equitação, buscando o desenvolvimento biopsicossocial de pessoas com deficiência e/ou com necessidades especiais.

A Associação de Pais e Amigos dos Excepcionais de Pelotas (APAE, 2015) descreve:

A equoterapia é um método terapêutico e educacional que utiliza o cavalo dentro de uma abordagem interdisciplinar, nas áreas da saúde, educação e equitação, buscando o desenvolvimento biopsicossocial das pessoas portadoras de necessidades especiais.

É nesse ambiente multidisciplinar que o estudo propõe analisar a existência ou não da cooperação entre os profissionais envolvidos, visando agregar e estimular o estudo da cooperação no ramo da saúde.

\section{Apresentação dos resultados e discussões}

A cooperação estudada no artigo foi proposta em um ambiente com indivíduos de diversas formações (e formações em andamento), no ramo da saúde, onde foi observado de que modo é nivelada 
essa cooperação e como está intrínseco, velado, os princípios do associativismo nesses profissionais.

Profissionais esses, que não obtiveram em sua formação o estudo formal direcionado para o cooperativismo, associativismo e tão pouco, a economia solidária. Escreve-se tão pouco, porque em um modelo capitalista onde a forma de se pensar e se organizar é baseada no individualismo e consumo, a visão de outros modelos de organizações e suas vivências, tornam-se algo imaginário e inatingível.

Sendo assim, a pesquisa aqui proposta é um levantamento de dados, com aplicação de questionário (APÊNDICE A), com perguntas abertas e fechadas, delineado por Gil (2010, p. 102): "Por questionário entende-se um conjunto de questões que são respondidas por escrito pelo pesquisado.", para os profissionais ligados à modalidade, da Associação no mês de julho do ano de 2016 e para o embasamento do estudo, revisão bibliográfica, que começou no ano de 2015.
A pesquisa bibliográfica é elaborada com base em material já publicado. Tradicionalmente, esta modalidade de pesquisa inclui material impresso, como livros, revistas, jornais, teses, dissertações e anais de eventos científicos (GIL, 2010, p. 29).

São vinte e um indivíduos envolvidos com a modalidade de equoterapia na associação, sendo que apenas um não respondeu ao questionário, por incompatibilidade de tempo. Dos vinte que participaram da pesquisa $35 \%$ ou 7 são voluntários, $55 \%$ ou 11 são contratados e $10 \%$ ou 2 são cedidos de outras instituições, assim como $55 \%$ ou 11 são representantes do sexo feminino.

As funções dos indivíduos pesquisados são demonstradas no Gráfico 1, pode-se analisar que a associação possui um ambiente multidisciplinar, como também, bastante acadêmico. Pode-se observar que $30 \%$ ou 6 dos pesquisados são estagiários, sendo que todos são do curso de fisioterapia.

\section{Gráfico 1 - Formação da equipe multidisciplinar}

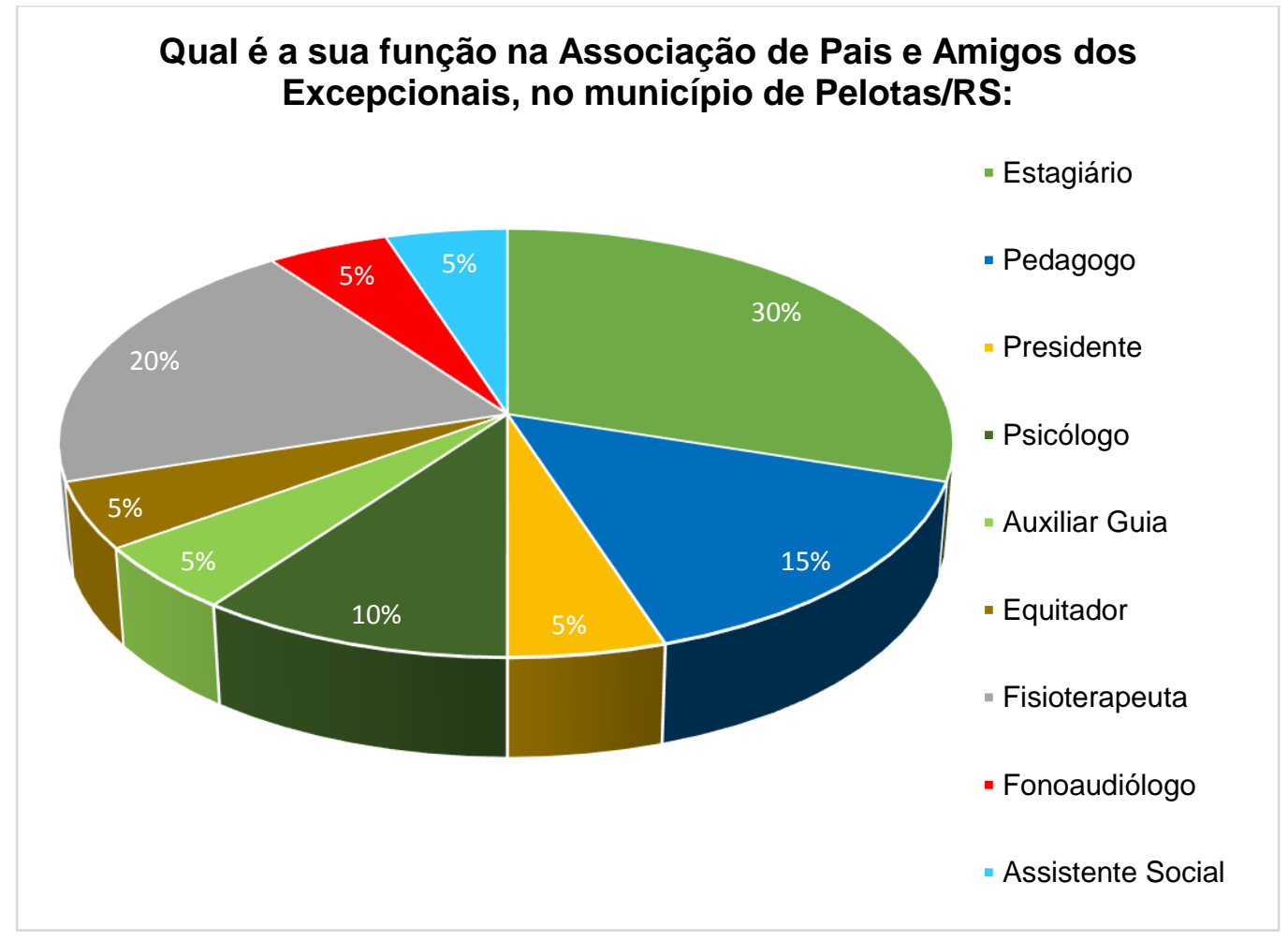

Fonte: Autoria Própria.

A pesquisa demonstrou, também, que o nível de escolaridade entre os envolvidos na pesquisa é muito significativo, $50 \%$ ou 10 possuem ensino superior, $5 \%$ ou 1 possui mestrado, $5 \%$ ou 1 possui doutorado, $30 \%$ ou 6 possuem ensino superior incompleto e apenas $10 \%$ ou 2 possuem ensino médio completo. 
O questionário foi aplicado na última reunião semanal que antecedeu ao recesso do meio do ano e na sede da equoterapia da Associação, de maneira individual. Essa reunião semanal acontece todas as terças-feiras pela manhã, onde os profissionais reúnem-se para discutir todos os pareceres que envolvem os pacientes da Associação.

Foi escolhido esse ambiente, primeiramente porque é o momento em que se consegue o maior número de profissionais reunidos para a efetivação do questionário e em segundo, porque é nesse momento que mesmo aqueles que não agem diretamente com a modalidade, nesse artigo analisada, tem a possibilidade de direcionar os pacientes para a mesma.

Logo, fazem parte do estudo contribuindo para a análise da cooperação na equipe. Pode-se verificar no Gráfico 2, os questionamentos colocados como objetivos nesse artigo, em que foi demonstrado que não há supremacia entre os profissionais da equipe, tampouco manipulações e ocultações de informações na reunião semanal.

Esse nivelamento de profissões entre a equipe é fundamental, principalmente para uma Associação.
Observou-se que as atuações são ativas tanto em participação, como na explanação de ideias e soluções. Todos cooperam, com o mesmo nível de importância, para o objetivo final, que é a qualidade de vida dos pacientes.

Por meio da pesquisa, também observou-se, que foi nulo o questionamento em relação a uma não gestão democrática pelos membros da presidência e diretoria, o que reforçou um ambiente em acordo com o fundamento de existência de uma associação, como a efetividade dos princípios que a regem.

Ainda vale ressaltar que a pesquisa verificou que apenas $5 \%$ ou um indivíduo realizou um curso específico sobre cooperativismo e associativismo. Ou seja, mesmo que a maioria dos profissionais não tenha obtido um embasamento de estudo formal do associativismo, do cooperativismo e da economia solidária, pode-se observar que esses profissionais estudados, respondem aos princípios do capitalismo no seu dia-a-dia, de forma contrária, porque o ambiente onde estão inseridos é de cooperação e esses não só a praticam como entendem que essa é a forma mais importante, naquele cenário, de atingir os objetivos propostos

\section{Gráfico 2 - Observações da reunião semanal}

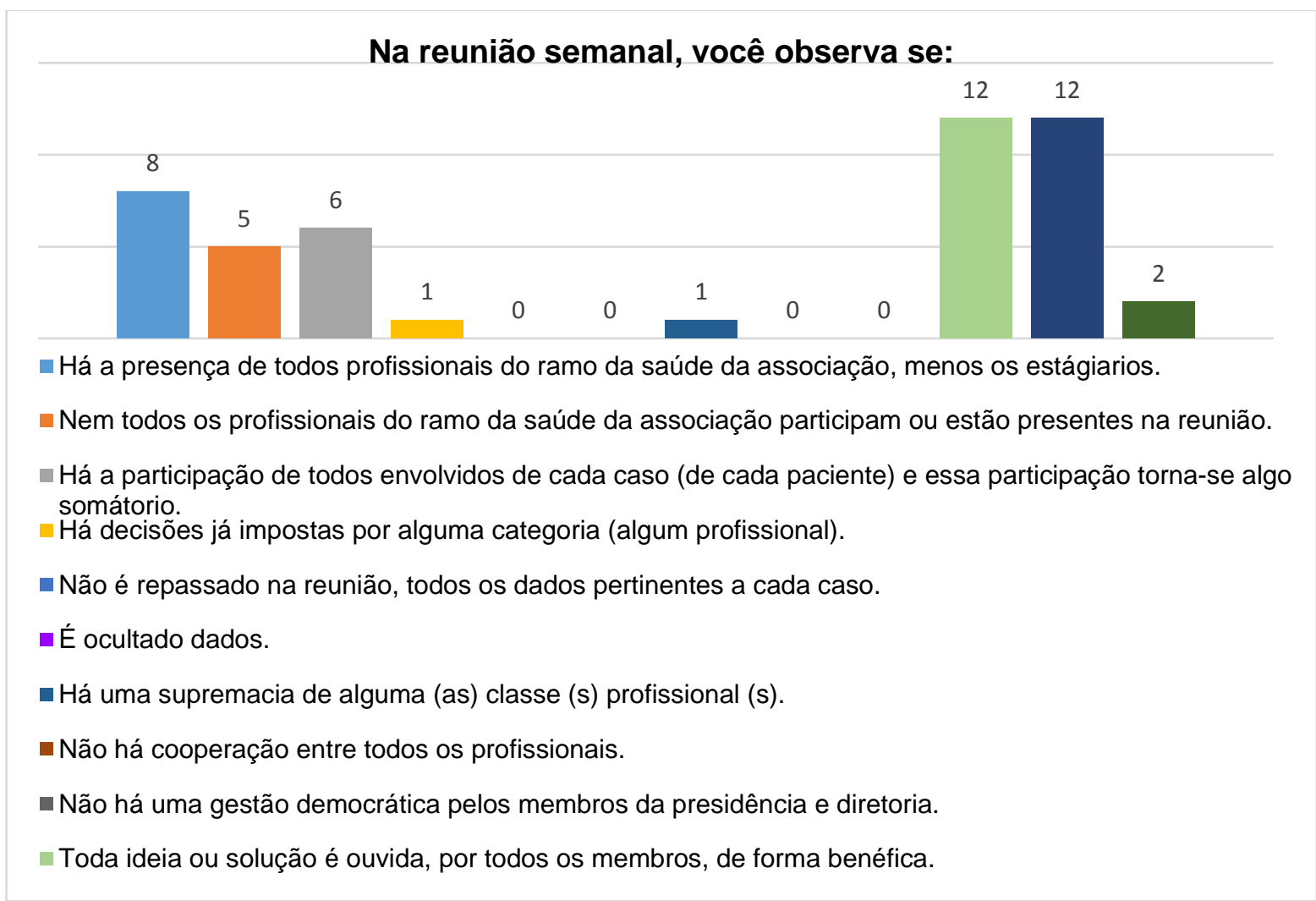

Fonte: Autoria própria. 
O que foi confirmado, também, quando questionados na questão, 'Analisando de forma organizacional, você consegue observar equidade nos profissionais que atuam na modalidade de equoterapia, em relação aos seus propósitos profissionais?', foi que $85 \%$ ou 17 dos envolvidos na pesquisa, responderam que sim, o que demonstra que não há disparidade entre os profissionais, uma das questões que é muito importante, ao tratar-se de um ambiente em que exige cooperação, igualdade, respeito e sinergia entre os mesmos.

Felizmente, o número de questionários respondidos foi relevante para a realização desse artigo, assim possibilitando uma visão sólida do que foi proposto. Quando questionados, todos os pesquisados responderam que acreditam na modalidade de equoterapia, assim como, todos também acreditam que a mesma, proporciona um ambiente cooperativo entre os profissionais que estão envolvidos.

Referente à questão 'Você acredita ser importante o estudo do cooperativismo $e$ associativismo?', verificou-se que todos os que participaram da pesquisa responderam que sim. A pergunta ainda tinha um segundo complemento, se caso a reposta fosse sim, se os mesmos acreditavam ser necessário anexar à grade curricular das instituições de ensino, o estudo do cooperativismo e associativismo, independentemente do país ter o regime capitalista e 5\% não responderam à mesma, $20 \%$ ou 4 responderam que não e $75 \%$ ou 15 responderam que sim.

O resultado acima, complementou a outro questionamento em que $90 \%$ ou 18 dos pesquisados, posicionaram-se a favor do fomento de organizações como cooperativas e associações, no ramo da saúde. Entretanto, como demonstrado pelo Gráfico 3, 65\% ou 13 responderam que não receberam informações sobre essas organizações, na formação acadêmica, o que fortalece o estudo desse artigo, ou seja, de que os indivíduos conhecem e por vezes, praticam a cooperação de forma superficial, sem relacionar esse entendimento na sua forma organizacional. $O$ conhecimento de organização e gestão não pode ser algo irrestrito, na esfera dos profissionais da saúde.

Gráfico 3 - Informações sobre receber instruções sobre cooperativas e associações, nas instituições de ensino

\section{Na sua formação acadêmica, você recebeu informações sobre cooperativas e associações?}

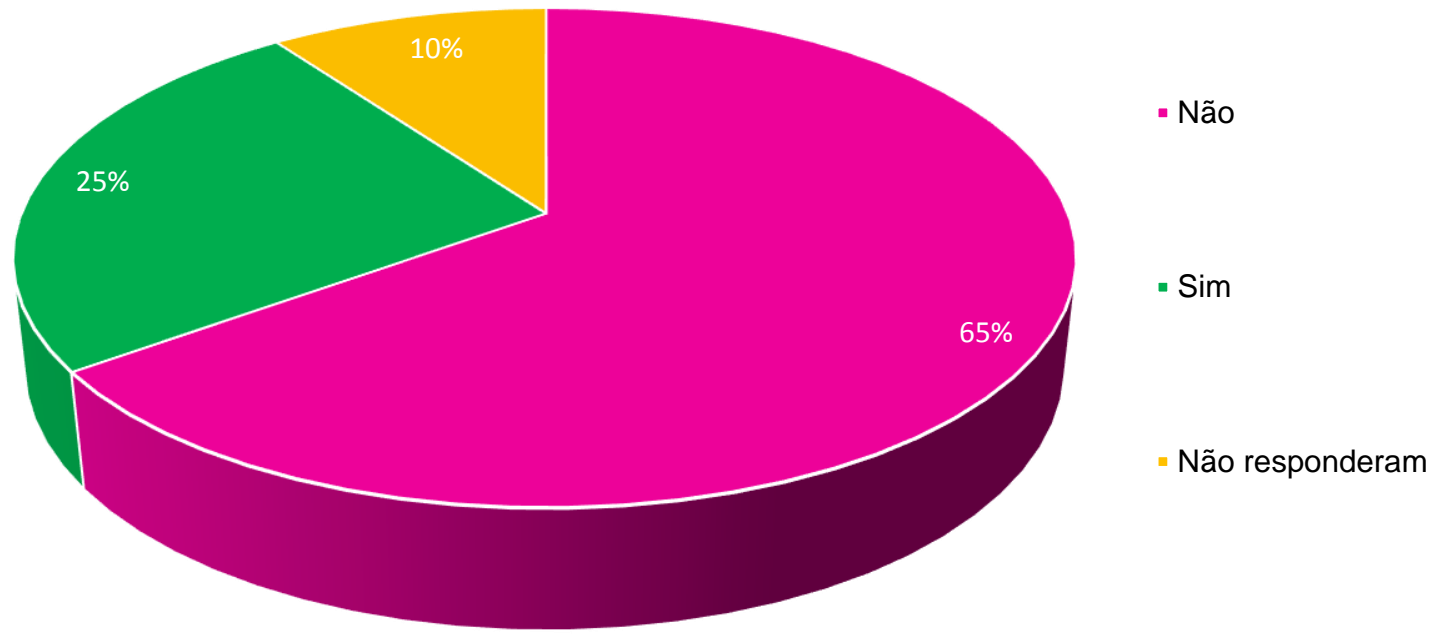

Fonte: Autoria própria. 
O que mais uma vez auxilia a consolidar a ideia do estudo do cooperativismo e associativismo, no ramo da saúde. O fomento à reflexão cooperativista e associativista de profissionais inseridos nesse ramo, é de proporcionar outras alternativas para que os indivíduos possam aprimorar-se não somente para a economia regional, mas também nas formas de organizações sociais, importantes para diversas estruturas.
No Gráfico 4, pode-se observar que dentre as alternativas propostas, apenas as três primeiras estão inseridas dentro dos princípios do associativismo. Dentro dos resultados a que se destaca em grande vantagem é o princípio do compromisso com a comunidade, o qual é a gênese da APAE e, possivelmente, pode-se dizer também, de todas as APAE. A Associação nasce e durante toda a sua existência, tem como a comunidade o seu berço e essência.

\section{Gráfico 4-A visão dos pesquisados perante a APAE}

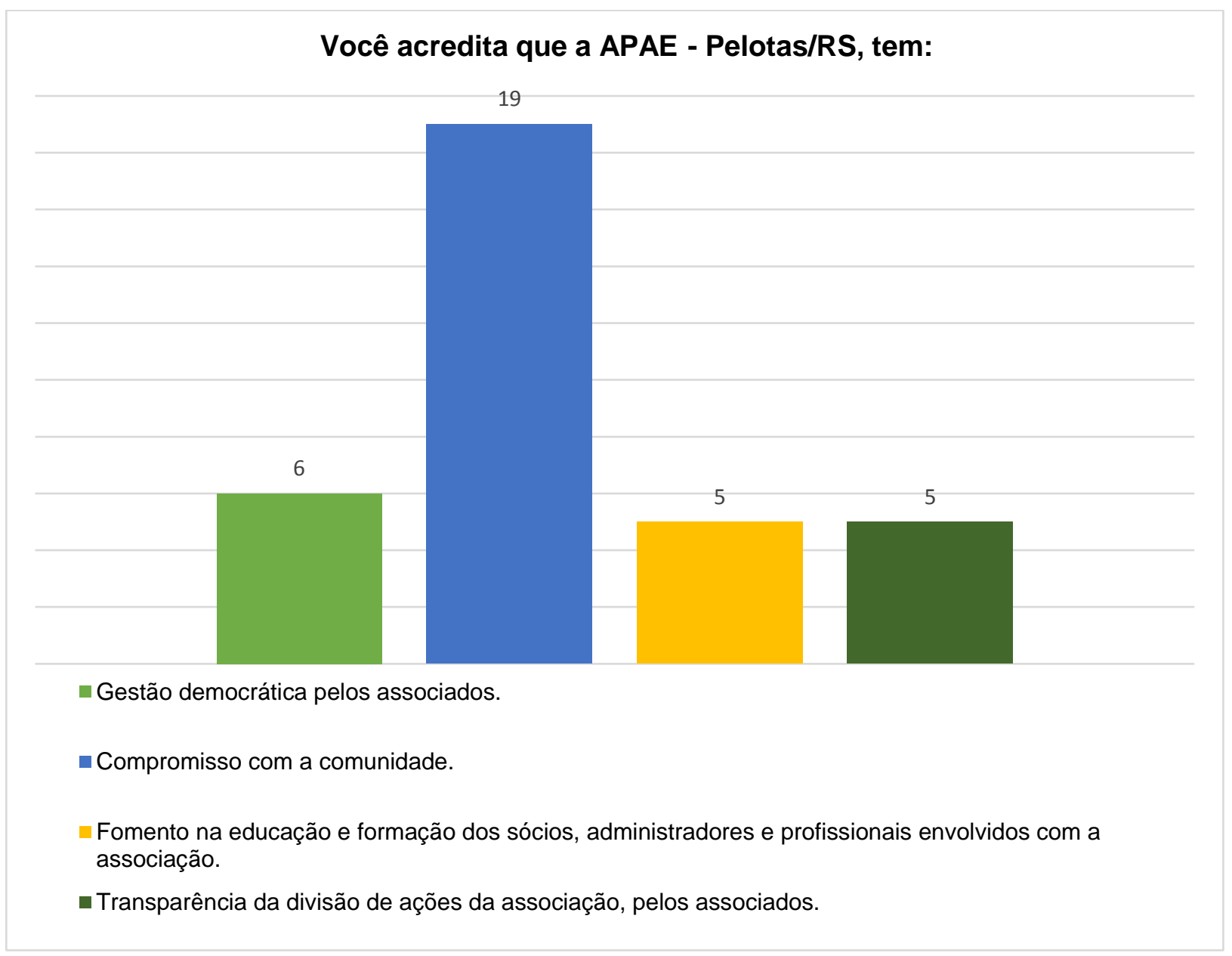

Fonte: Autoria própria.

A pesquisa mostrou que $35 \%$ ou 7 dos pesquisados trabalha na associação há mais de vinte anos, $15 \%$ ou 3 entre quinze e vinte anos, seguidos de $5 \%$ ou 1 entre cinco e dez anos, $10 \%$ ou 2 entre um e cinco anos e $35 \%$ ou 7 até um ano. Não há uma rotatividade exacerbada de indivíduos, o que demonstra que a Associação é um ambiente, verdadeiramente com o foco no capital humano.
Por fim, demonstra-se pelo Gráfico 5 a visão dos indivíduos pesquisados, em relação ao que acreditam deter aqueles que trabalham nessas organizações. Observa-se que o trabalho em equipe é o preponderante, seguidos da colaboração e empatados, a cooperação, participação ativa e responsabilidade social.

Em relação à questão de a colaboração vir antes da cooperação, nesse caso, acredita-se que 
unicamente seja pela falta de conhecimento, da diferenciação entre ambos os termos, fato já mencionado anteriormente nesse artigo, sobre a utilização errônea entre os mesmos.

O Gráfico 5, demonstrou positivamente, que apesar de os indivíduos não obterem conhecimento formal específico sobre a cooperação e organizações, estes as praticam e consideram importantes os seus princípios. Exemplo disso foi o número significativo expresso no gráfico de adesão voluntária e livre, ajuda mútua e empatia.

\section{Gráfico 5 - A visão dos pesquisados perante as organizações associativistas e cooperativas}

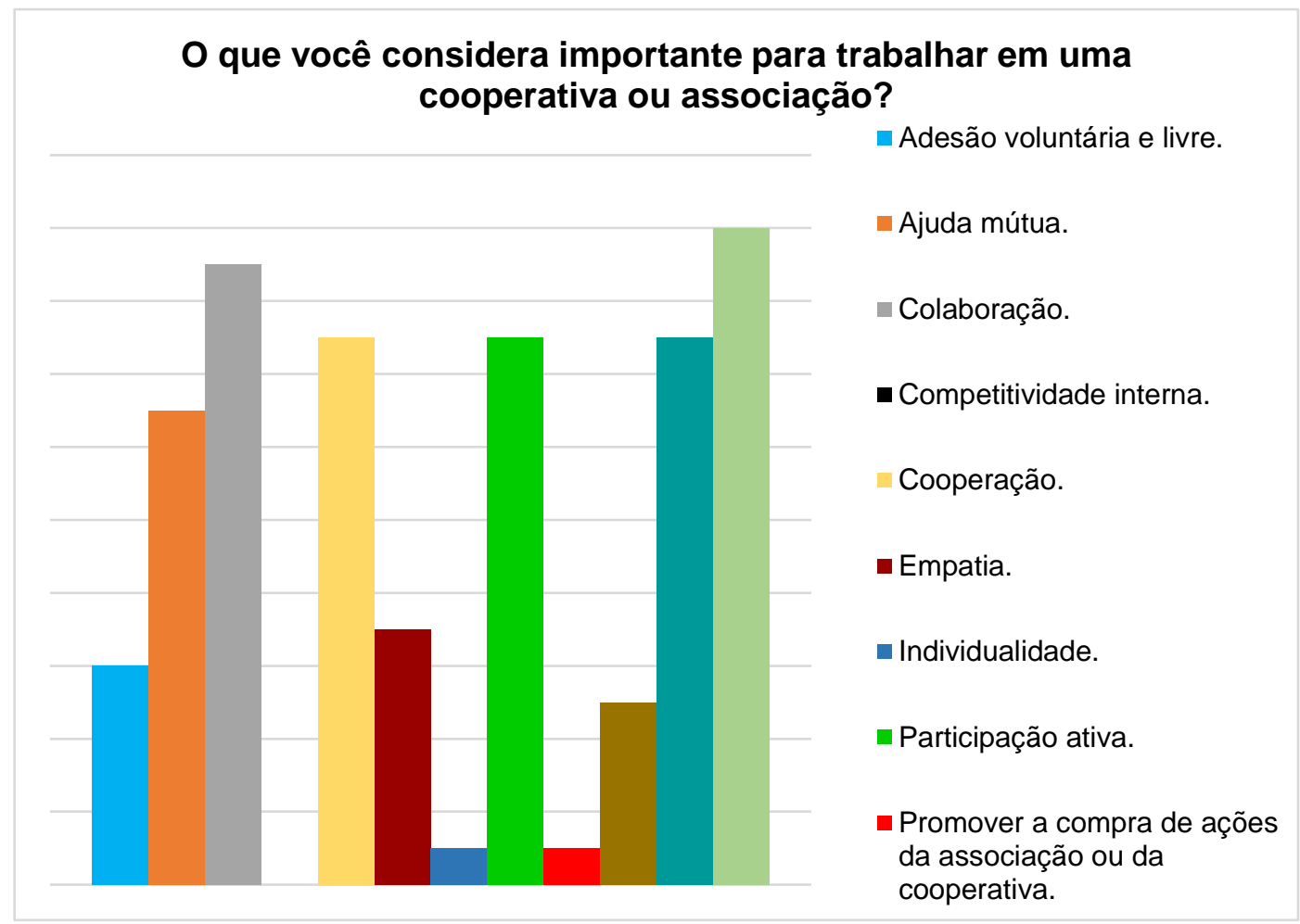

Fonte: Autoria própria

\section{Considerações finais}

O artigo apresentou um estudo da cooperação na equipe multidisciplinar, realizada na Associação de Pais e Amigos dos Excepcionais (APAE), no município de Pelotas, Rio Grande do Sul, especificamente focalizando a modalidade de equoterapia. O estudo é um levantamento de dados, delineado por Gil (2010), com aplicação de questionários com perguntas abertas e fechadas aos profissionais envolvidos com a modalidade, no mês de julho do ano de 2016 e para o embasamento do mesmo, foi realizada revisão bibliográfica que começou no ano de 2015 até agosto de 2016.

A pesquisa demonstrou que dos 20 indivíduos questionados, $85 \%$ ou 17 desses demonstraram que não há disparidade entre os profissionais, um dos questionamentos colocados para a análise neste artigo. Outra questão importante que a pesquisa evidenciou foi a de que todos os pesquisados acreditam na modalidade de equoterapia, como também, os mesmos, $100 \%$ ou 20 indivíduos, acreditam que o ambiente da equoterapia é um ambiente cooperativo.

Todos os que participaram da pesquisa acreditam, também, ser importante o estudo do cooperativismo. Outro dado expresso pela pesquisa é de que $75 \%$ ou 15 dos indivíduos pesquisados, acreditam ser importante anexar a grade curricular das instituições de ensino o estudo do cooperativismo e associativismo.

Apesar da complexidade do termo de 'cooperação' inserido no ramo da saúde, constatouse, a efetividade dos princípios associativistas, intrínsecos na relação de cooperação entre a equipe da Associação, como se refletiu sobre a importância 
do estudo aprofundado dessas organizações, para profissionais do ramo.

Profissionais esses do mesmo ramo, entretanto, com formações diferentes, singulares entre si, no entanto, conforme a pesquisa bem demonstrou, capazes de vislumbrar para além da visão capitalista. Esses indivíduos, nessa associação e aqueles que estão relacionados a essa modalidade estudada, contrapõem o consumismo, a rivalidade e o individualismo do modelo atual com uma outra lógica de trabalho.

Por isso, reflete-se por um estudo mais significativo a esses profissionais. $\mathrm{O}$ fomento à reflexão cooperativista e associativista de profissionais inseridos no ramo da saúde, é de proporcionar outras alternativas para que esses indivíduos possam aprimorar-se, não somente para a economia regional, mas também nas formas de organizações sociais, importantes para diversas estruturas.

\section{Referências}

ABRANTES, José. Associativismo e Cooperativismo, Como a união de pequenos empreendedores pode gerar emprego e renda no Brasil. Rio de Janeiro: Interciência. 2004.

ANDE - BRASIL. Associação Nacional de Equoterapia. Disponível em: <http://equoterapia.org.br>. Acesso de: 2 nov. 2015.

APAE - PELOTAS. Associação de Pais e Amigos dos Excepcionais de Pelotas/Rio Grande do Sul. Disponível em: <http://www.apaepel.org.br>. Acesso em: 2 nov. 2015.

BAQUERO, Rute Vivian Angelo. Empoderamento: Instrumento de Emancipação Social? - uma discussão conceitual. Disponível em:

<http://www.seer.ufrgs.br/debates/article/view File/26722/17099>. Acesso em: 30 ago. 2016.

BURNS, Edwart McNall. História da civilização ocidental, do homem das cavernas até a bomba atômica. 2. ed. Rio de Janeiro, Porto Alegre, São Paulo: Editora Globo. 1967.
BRANCO, Manoel Mafra Castelo; MORAIS, Roberto Tadeu Ramos. O Conselho Fiscal no processo da governança em cooperativa de crédito: estudo de Caso na Unicred (União Nacional das Cooperativas) e a Singular Unicred Manaus. Reflexão cooperativista. $\quad N^{\circ} 2$. ESCOOP. 2014.

CENTRO DE EQUOTERAPIA DE URUGUAIANA GEN. FIDÉLIS. Disponível em: <http://www.equogenfidelis.org.br>. Acesso em: 7 jul. 2016.

CINTRA, André Galvão. Raças de cavalos criadas no Brasil. Disponível em: $<$ http://www.sna.agr.br/uploads/AnimalBusines s_05_07.pdf $>$. Acesso em: 31 ago. 2016.

GIL, Antônio Carlos. Como elaborar projetos de pesquisa. 5. ed. São Paulo. Atlas. 2010.

GOMES, Romeu; DESLANDES, Suely Ferreira. Interdisciplinaridade na saúde pública: um campo em construção. Disponível em: <http://www.scielo.br/scielo.php?script=sci_art text\&pid=S0104-11691994000200008>. Acesso em: 7 fev. 2016.

GUSMÃO, Sebastião. História da Medicina: evolução e importância. Disponível em: $<$ http://www.museuemigrantes.org/docs/conhecimento/Historia_da _medicina.pdf $>$. Acesso em: 30 ago. 2016.

LIMA, Ana Carla de. A representação social da interdisciplinaridade para os profissionais que atuam na equoterapia. Disponível em: $<$ http://site.ucdb.br/public/mddissertacoes/7752-a-representacao-social-dainterdisciplinaridade-para-os-profissionais-queatuam-com-equoterapia.pdf $>$. Acesso em: $8 \mathrm{fev}$. 2016.

LIMA, Ludmila Moreira. Cooperação, o que vem a ser? Disponível em: <http://www.unieuro.edu.br/sitenovo/revistas/d ownloads/hegemonia_02_02.pdf >. Acesso em: 7 fev. 2016. 
MATUDA, Carolina Guinoza; AGUIAR, Dulce Maria de Lucena; FRAZÃO, Paulo. Cooperação interprofissional e a reforma sanitária no Brasil: implicações para o modelo de atenção à saúde. Disponível em: <http://www.scielo.br/scielo.php?script=sci_art text\&pid=S0104-12902013000100016>.

Acesso em: 7 fev. 2016.

OCERGS. Organização das cooperativas do Rio Grande do Sul. Disponível em: <http://www.ocergs.coop.br/>. Acesso em: 5 jul. 2016.

SANTANA, José Paranaguá de. Um olhar sobre a Cooperação Sul-Sul em Saúde. Disponível em: <http://www.scielo.br/scielo.php?pid=S1413$81232011000600037 \&$ script=sci_arttext $>$. Acesso em: 7 fev. 2016.

SCHERER, Magda Duarte dos Anjos; PIRES, Denise; SCWARTZ, Yves. Trabalho coletivo um desafio para a gestão em saúde. Disponível em: <http://www.scielo.br/scielo.php?pid=S0034$89102009000400020 \&$ script=sci_arttext $>$. Acesso em: 7 fev. 2016.

SEVERO, José Torquato. Equoterapia: Equitação que promove a saúde e a educação. Disponível em:

$<$ http://www.actafisiatrica.org.br/audiencia_pdf .asp? aid2 $=358 \&$ nomeArquivo $=v 4 n 3 a 06 . p d f>$. Acesso em: 11 jul. 2016.

TAVARES, Suyane Oliveira; VENDRÚSCOLO, Cláudia Tomasi; KOSTULSKI, Camila Almeida; GONÇALVES, Camila dos Santos. Interdisciplinaridade, Multidisciplinaridade ou Transdisciplinaridade. Disponível em: <http://www.unifra.br/eventos/interfacespsicol ogia/Trabalhos/3062.pdf>. Acesso em: 30 maio 2016.

WINCLER, Natália Carrão; MOLINARI, Gisele Trindade. Competição, Colaboração, Cooperação e Coopetição: revendo os Conceitos em Estratégias Interorganizacionais. Disponível em: <http://www.admpg.com.br/revista2011/artigos 19.pdf>. Acesso em: 7 fev. 2016. 